\section{Dementia

\title{
Geographical Variation in Dementia Mortality in Italy, New Zealand, and Chile: The Impact of Latitude, Vitamin D, and Air Pollution
}

\author{
Tom C. Russ ${ }^{a-d}$ Laura Murianni ${ }^{e} \quad$ Gloria Icaza $^{f} \quad$ Andrea Slachevsky $^{g-i}$ \\ John M. Starr ${ }^{a, b}$ \\ ${ }^{a}$ Alzheimer Scotland Dementia Research Centre, ${ }^{b}$ Centre for Cognitive Ageing and \\ Cognitive Epidemiology, 'Division of Psychiatry, Centre for Clinical Brain Sciences, and \\ ${ }^{\mathrm{d}}$ Centre for Dementia Prevention, University of Edinburgh, Edinburgh, UK; ${ }^{\mathrm{e}} \mathrm{Health}$ \\ Statistics Unit, National Institute of Statistics, Rome, Italy; Instituto de Matemática y \\ Física, Universidad de Talca, Talca, and 9Physiopathology Department, ICBM and East \\ Neuroscience Department, Faculty of Medicine, University of Chile, h' Cognitive Neurology \\ and Dementia, Neurology Department, Hospital del Salvador, and 'Gerosciences Centre for \\ Brain Health and Metabolism, Providencia, Chile
}

\section{Key Words}

Dementia · Alzheimer's disease · Geographical variation · Epidemiology

\begin{abstract}
Background: Dementia risk is reported as being higher in the north compared to the south, which may be related to vitamin D deficiency. If this were the case, an opposite gradient of risk would be observed in the southern hemisphere, but this has not been investigated previously. Methods: We calculated standardised mortality ratios (SMRs) for deaths in 2012 where dementia (Alzheimer's disease, vascular or unspecified dementia) was recorded as the underlying cause for 20 regions in Italy, 20 District Health Board areas in New Zealand and 29 Health Service areas in Chile. Results: Dementia SMRs were higher in northern than central or southern Italy. The inverse pattern was seen in women in New Zealand, with rates higher on South Island than North Island. However, dementia risk was raised in eight regions in the north and centre of Chile in both men and women. Conclusions: Geographical variation plays a key role in dementia risk, but patterns vary in men and women. In the northern hemisphere, dementia mortality is higher in the north, but the pattern in the southern hemisphere is more complex.


Russ et al.: Geographical Variation in Dementia Mortality in Italy, New Zealand, and Chile: The Impact of Latitude, Vitamin D, and Air Pollution

\section{Introduction}

Dementia is a major global public health issue, and the number of people affected is projected to increase dramatically in the future [1]. Alzheimer's disease remains the commonest cause of dementia, but many cases of dementia are of mixed aetiology, and there is evidence of substantial overlap in risk factors for vascular and neurodegenerative causes of dementia [2]. Preventing dementia from developing or delaying the onset of clinical symptoms would substantially reduce disease numbers [3]. However, the aetiology of dementia is not fully understood: known and unknown genetic factors and the commonest risk factors (diabetes, midlife hypertension and obesity, smoking, depression, cognitive inactivity, and low educational attainment) do not fully explain dementia risk [4, 5]. The geographical distribution of dementia cases is not random; several studies have reported higher rates in the north compared to the south in the northern hemisphere [6-12]. One suggested explanation for this gradient of risk by latitude is relative insufficiency of vitamin D related to sunlight exposure [13-17]. We hypothesised that if this mechanism does contribute to dementia risk, the opposite latitudinal gradient should be observed in southern hemisphere settings. However, we are unaware of any studies in the southern hemisphere. Thus, we present the first such analysis using publicly available mortality data to compare Italy, New Zealand, and Chile.

\section{Methods}

We obtained regional dementia mortality and population data from the Italian National Institute of Statistics (http://dati.istat.it/), the New Zealand Ministry of Health (http://www.health.govt.nz/), and the Chilean Ministry of Health (http://www.deis.cl/). Data for selected mortality outcomes in New Zealand are available through the Ministry of Health website, but age-specific dementia data were provided on request. We identified deaths where ICD-10 codes F01 and F03 (vascular and unspecified dementia) and G30 (Alzheimer's disease) were recorded as the underlying cause of death. The latest data available in Italy were from 2012 for the total population (all ages) of each of the 20 regions of Italy. New Zealand data covered all 20 District Health Boards in 2012; we selected the population aged 50 years or older and excluded Maori and Pacific peoples to ensure broad comparability between the populations in Italy and New Zealand. Chilean dementia data from 2012 were obtained for the total population of the 29 Health Service areas covering the whole country.

From these data we calculated standardised mortality ratios (SMRs) with accompanying 95\% confidence intervals (CIs) for dementia in all regions of all three countries using the standard method [18]. SMRs were also calculated for Alzheimer's disease and vascular dementia where possible. These SMRs were then mapped in $\mathrm{R}$ for Windows version 3.2.3 using the ggplot2 package [19].

\section{Results}

From a total Italian population of 59 million (52\% female) in 2012, there were 15,701 vascular or unspecified dementia deaths plus 10,823 Alzheimer's disease deaths (total for all dementias: 26,524). We found dementia SMRs to be increased in the north of Italy (men: 107, 95\% CI 104-111; women: 115, 95\% CI 113-117) and lower in the south (men: 79, 95\% CI 75-83; women: $71,95 \% \mathrm{CI} 68-73$ ) compared to the centre of the country (men: $103,95 \% \mathrm{CI}$ 98-108; women: 102, 95\% CI 99-105) (fig. 1, table 1), but the pattern for Alzheimer's disease suggested an increased risk in the centre of Italy (online suppl. fig. 1; for all online suppl. material, see www.karger.com/doi/10.1159/000447449).

Of 1.4 million non-Maori, non-Pacific peoples New Zealanders aged 50 years or older (52\% female), 1,582 died with dementia in 2012 (including 529 with Alzheimer's disease and 
Russ et al.: Geographical Variation in Dementia Mortality in Italy, New Zealand, and Chile: The Impact of Latitude, Vitamin D, and Air Pollution

Table 1. Dementia SMRs (95\% CIs) by region of Italy

\begin{tabular}{|c|c|c|c|c|}
\hline \multirow[t]{2}{*}{ Region } & \multicolumn{2}{|l|}{ All dementias } & \multicolumn{2}{|c|}{ Alzheimer's disease } \\
\hline & men & women & men & women \\
\hline North & $107(104-111)$ & $115(113-117)$ & $93(88-98)$ & $101(97-104)$ \\
\hline Centre & $103(98-108)$ & $102(99-105)$ & $118(110-126)$ & $117(112-123)$ \\
\hline South & $79(75-83)$ & $71(68-73)$ & $92(86-98)$ & $84(79-88)$ \\
\hline Islands & $110(104-117)$ & $97(93-101)$ & $115(105-126)$ & $101(94-108)$ \\
\hline \multicolumn{5}{|l|}{ North-West } \\
\hline Piemonte & $118(110-127)$ & $120(115-126)$ & $92(81-104)$ & $90(83-99)$ \\
\hline Valle d'Aosta/Vallée d'Aoste & $101(63-160)$ & $179(142-227)$ & $155(88-274)$ & $163(110-242)$ \\
\hline Liguria & $151(136-169)$ & $153(142-164)$ & $154(131-182)$ & $159(143-178)$ \\
\hline Lombardia & $90(85-95)$ & $104(100-108)$ & $101(93-109)$ & $115(110-122)$ \\
\hline \multicolumn{5}{|l|}{ North-East } \\
\hline Trentino-Alto Adige/Südtirol & $88(74-104)$ & $102(91-114)$ & $90(70-117)$ & $85(70-103)$ \\
\hline Veneto & $116(109-125)$ & $122(116-128)$ & $87(77-98)$ & $93(85-101)$ \\
\hline Friuli-Venezia Giulia & $93(80-109)$ & $111(101-122)$ & $50(37-70)$ & $86(72-102)$ \\
\hline Emilia-Romagna & $118(110-127)$ & $114(108-120)$ & $73(63-84)$ & $72(65-80)$ \\
\hline \multicolumn{5}{|l|}{ Centre } \\
\hline Toscana & 117 (108-127) & $118(112-125)$ & 138 (124-155) & $145(135-157)$ \\
\hline Umbria & $125(106-146)$ & $124(111-138)$ & $144(115-180)$ & $121(102-143)$ \\
\hline Marche & $147(131-164)$ & $133(123-143)$ & $142(119-168)$ & $135(120-153)$ \\
\hline Lazio & $78(72-84)$ & $79(75-84)$ & $93(83-104)$ & $93(86-100)$ \\
\hline \multicolumn{5}{|l|}{ South } \\
\hline Abruzzo & $123(108-140)$ & $128(117-139)$ & $141(117-170)$ & $156(138-177)$ \\
\hline Molise & $106(80-142)$ & $87(70-108)$ & $121(80-182)$ & $106(77-144)$ \\
\hline Campania & $59(54-64)$ & $54(51-57)$ & $68(59-77)$ & $64(58-70)$ \\
\hline Puglia & $89(81-97)$ & $78(73-83)$ & $108(96-122)$ & $99(91-108)$ \\
\hline Basilicata & $89(71-112)$ & $63(53-76)$ & $110(81-151)$ & $75(57-98)$ \\
\hline Calabria & $80(70-91)$ & $67(61-74)$ & $86(70-104)$ & $62(52-72)$ \\
\hline \multicolumn{5}{|l|}{ Islands } \\
\hline Sicilia & $104(97-112)$ & $89(85-94)$ & $109(97-121)$ & $88(81-96)$ \\
\hline Sardegna & $128(115-144)$ & $121(111-131)$ & 136 (115-161) & $138(123-156)$ \\
\hline
\end{tabular}

332 with vascular dementia; the subtype was not specified for the remainder). There was little difference in SMR between North and South Islands in men (North Island: 101, 95\% CI 92-111; South Island: 96, 95\% CI 82-113), but in women dementia SMRs were higher on South Island than North Island (North Island: 95, 95\% CI 89-102; South Island: 114, 95\% CI 102-127) (fig. 2, table 2). However, these differences were not as clear for Alzheimer's disease (online suppl. fig. 2) or vascular dementia (online suppl. fig. 3).

Of 17.4 million people in Chile (51\% female), there were 3,852 dementia deaths in 2012 (including 1,585 Alzheimer's disease deaths). Dementia SMRs were increased in the Norte Grande (men: 126, 95\% CI 100-159; women: 130, 95\% CI 112-169) and the Zona Central, which includes the Santiago Metropolitan Region (men: 105, 95\% CI 99-112; women: 104, 95\% CI 99-110) and were generally reduced elsewhere (fig. 3a, table 3). SMRs were even higher in the Santiago Metropolitan Region itself (men: 128, 95\% CI 118-139; women: 114, 95\% CI 108-125) (fig. 3b) than in the rest of the Zona Central. The observed pattern was less marked for Alzheimer's disease (table 3, online suppl. fig. 4), with no increase in SMRs in the Norte Grande, but SMRs remaining raised in the Santiago Metropolitan Region, particularly in men (men: 122, 95\% CI 107-139; women: 109, 95\% CI 100-126). 
Russ et al.: Geographical Variation in Dementia Mortality in Italy, New Zealand, and

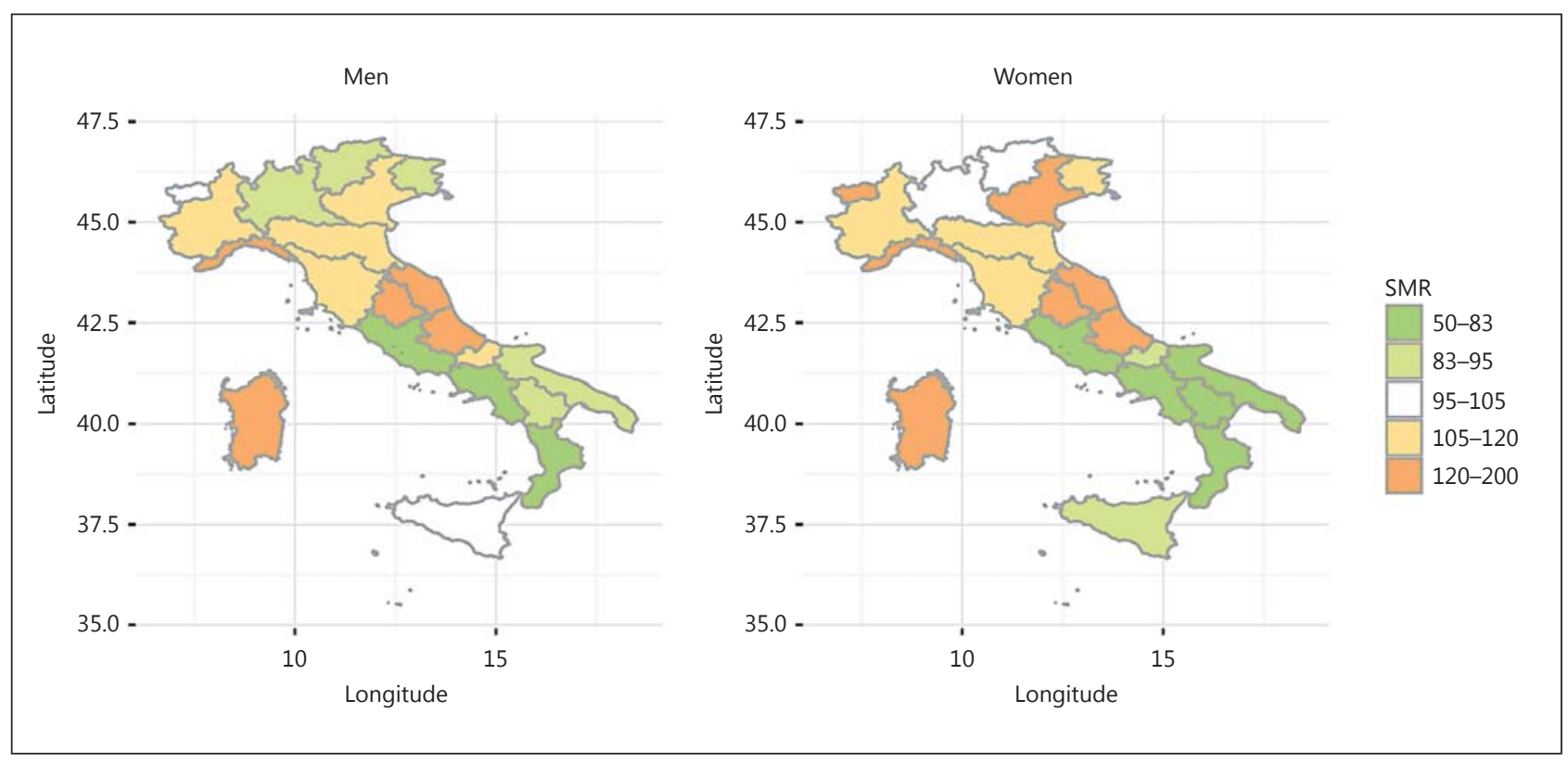

Fig. 1. Dementia SMRs by region of Italy for men and women.

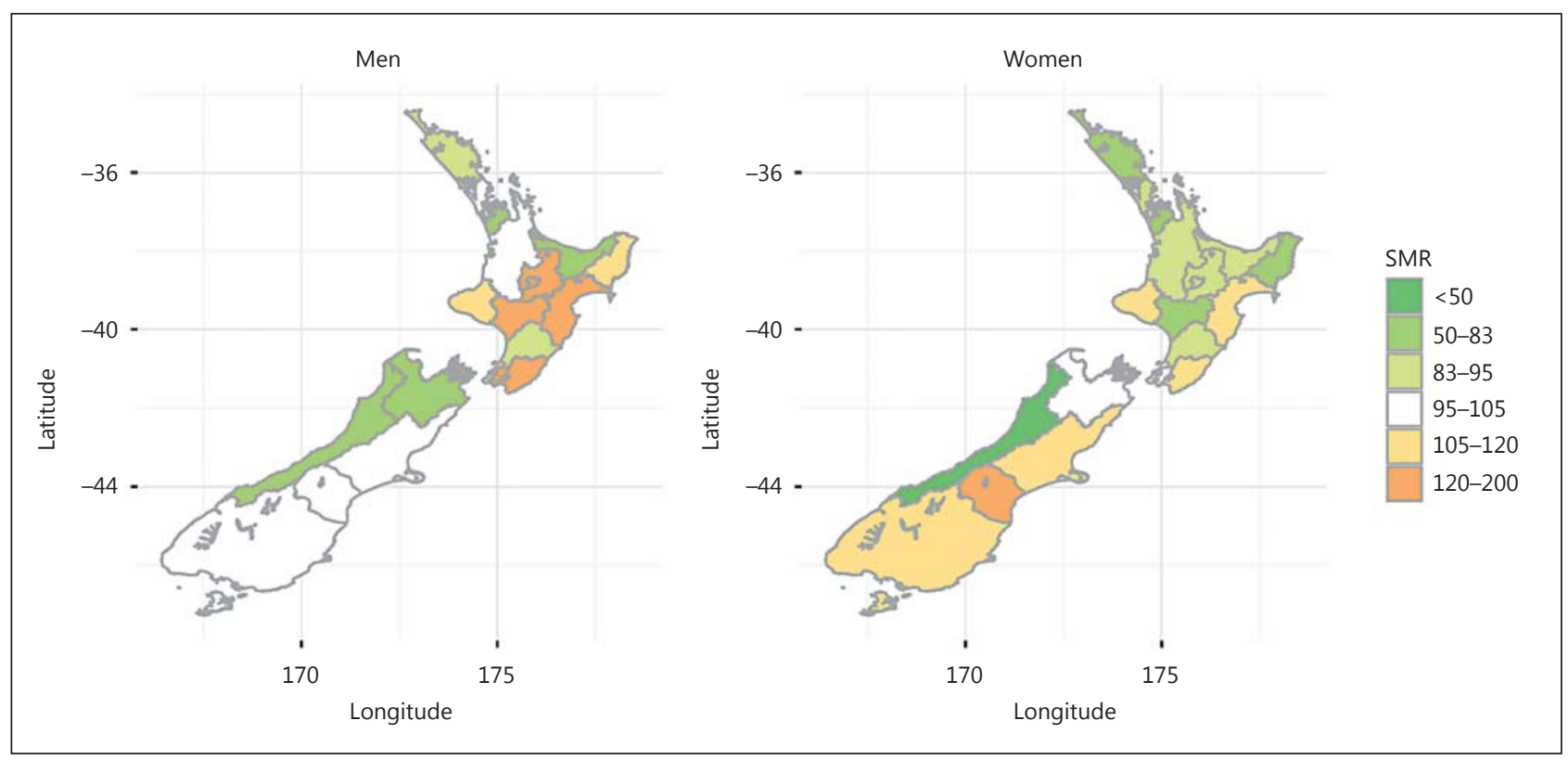

Fig. 2. Dementia SMRs by District Health Board of New Zealand for men and women (population aged 50 years and older).

\section{Discussion}

We found increased dementia SMRs in the north of Italy compared to the south, a possible inverse pattern in New Zealand - higher rates in the south compared to the north - at least in women, but increased SMRs in central and northern Chile. 
Russ et al.: Geographical Variation in Dementia Mortality in Italy, New Zealand, and Chile: The Impact of Latitude, Vitamin D, and Air Pollution

Table 2. Dementia SMRs (95\% CIs) by District Health Board of New Zealand (population aged 50 years and older)

\begin{tabular}{|c|c|c|c|c|c|c|}
\hline \multirow[t]{2}{*}{ District Health Board } & \multicolumn{3}{|l|}{ Men } & \multicolumn{3}{|l|}{ Women } \\
\hline & all dementias & $\mathrm{AD}$ & VD & all dementias & $\mathrm{AD}$ & VD \\
\hline North Island & $101(92-111)$ & $94(79-112)$ & $100(82-121)$ & $95(89-102)$ & $96(85-109)$ & $97(82-115)$ \\
\hline South Island & $96(82-113)$ & $117(90-153)$ & $101(73-140)$ & $114(102-127)$ & $112(92-136)$ & $109(82-143)$ \\
\hline \multicolumn{7}{|l|}{ North Island } \\
\hline Northland & $90(60-136)$ & $124(67-231)$ & $48(15-148)$ & $73(53-101)$ & $80(45-141)$ & $73(33-162)$ \\
\hline Waitemata & $104(82-132)$ & $86(54-137)$ & $92(55-153)$ & $94(79-112)$ & $76(53-108)$ & $120(83-176)$ \\
\hline Auckland & $121(94-156)$ & $130(84-201)$ & $125(75-207)$ & $136(115-161)$ & $127(92-174)$ & $207(148-289)$ \\
\hline Counties Manukau & $60(43-85)$ & $48(24-96)$ & $84(47-152)$ & $69(55-87)$ & $87(60-126)$ & $40(19-83)$ \\
\hline Waikato & $102(77-135)$ & $78(44-136)$ & $108(63-186)$ & $95(78-116)$ & $114(82-160)$ & $49(25-98)$ \\
\hline Lakes & $131(83-208)$ & $253(140-457)$ & $89(29-275)$ & $95(65-139)$ & $120(65-223)$ & $66(21-203)$ \\
\hline Bay of Plenty & $78(53-116)$ & $79(40-158)$ & $63(26-153)$ & $92(71-118)$ & $81(49-132)$ & $83(43-159)$ \\
\hline Tairawhiti & $116(55-242)$ & $157(51-486)$ & $134(34-536)$ & $58(27-121)$ & $135(56-325)$ & - \\
\hline Hawke's Bay & $146(104-205)$ & $168(95-295)$ & $126(60-264)$ & $110(83-144)$ & $142(91-219)$ & $90(43-189)$ \\
\hline Taranaki & $106(66-170)$ & $59(19-183)$ & $101(38-269)$ & $112(81-155)$ & $61(28-137)$ & $205(114-370)$ \\
\hline MidCentral & $90(59-138)$ & $54(20-145)$ & $210(119-369)$ & $87(64-118)$ & $97(58-165)$ & $127(68-236)$ \\
\hline Whanganui & $149(88-251)$ & $67(17-269)$ & $86(22-345)$ & $52(28-97)$ & $17(2-122)$ & $31(4-223)$ \\
\hline Capital and Coast & $84(58-122)$ & $57(26-127)$ & $98(49-195)$ & $101(80-128)$ & $82(51-132)$ & $88(47-164)$ \\
\hline Hutt & $138(94-205)$ & $140(70-280)$ & $90(34-240)$ & $102(74-141)$ & $100(56-181)$ & $83(35-199)$ \\
\hline Wairarapa & $130(68-249)$ & $46(6-324)$ & - & $109(66-182)$ & $144(65-321)$ & - \\
\hline \multicolumn{7}{|l|}{ South Island } \\
\hline Nelson Marlborough & $74(46-119)$ & $83(37-184)$ & $53(17-165)$ & $100(75-134)$ & $73(39-136)$ & $107(53-214)$ \\
\hline West Coast & $73(27-194)$ & - & $74(10-525)$ & $42(16-113)$ & $35(5-247)$ & - \\
\hline Canterbury & $104(82-131)$ & $127(87-185)$ & $145(97-216)$ & $119(102-139)$ & $125(95-165)$ & $148(105-208)$ \\
\hline South Canterbury & $104(56-194)$ & $132(50-352)$ & $42(6-301)$ & $153(106-220)$ & $104(47-232)$ & $158(66-379)$ \\
\hline Southern & $97(72-131)$ & $132(83-209)$ & $75(38-150)$ & $112(91-137)$ & $121(85-173)$ & $50(24-105)$ \\
\hline
\end{tabular}

$\mathrm{AD}=$ Alzheimer's disease; $\mathrm{VD}=$ vascular dementia .

\section{Comparison with the Literature}

Several studies have described higher rates of dementia in the north compared to the south of Finland, England, Sweden, Scotland, Newfoundland, and China [7-12]. However, to the best of our knowledge, nothing has previously been published on geographical variation in dementia rates in the southern hemisphere.

\section{Limitations and Strengths}

These analyses were based on publicly available mortality data and therefore have their limitations. Death certification is widely used in epidemiological studies to identify cases of dementia, though any mention of dementia on the death certificate is considered a better dependent variable than instances when dementia is recorded as the underlying cause of death, since many people with dementia die from something else [20,21]. Although this methodology has previously been criticised [22], more recent studies suggest that dementia reporting on death certificates is improving and seems to be sufficiently robust for epidemiological purposes, see for example a false-negative rate of $18 \%$ in a memory clinic population $[12,20]$. However, death certification probably remains less reliable in identifying dementia subtype; for example, while Alzheimer's disease is by far the commonest cause of dementia, in Italy the proportion of cases denoted as Alzheimer's disease ranged from 23 to 67\% (median 45\%), the figures in New Zealand were 0-71\% (median 32\%) and in Chile 11-59\% (median 42\%). Thus, the findings for dementia subtype must be interpreted in the light of this fact, and the differences in the patterns seen for all dementias may be related to the accuracy 
Table 3. Dementia SMRs ( $95 \%$ CIs) by region of Chile

\begin{tabular}{|c|c|c|c|c|}
\hline \multirow[t]{2}{*}{ Region } & \multicolumn{2}{|l|}{ All dementias } & \multicolumn{2}{|c|}{ Alzheimer's disease } \\
\hline & men & women & men & women \\
\hline \multicolumn{5}{|l|}{ Natural region $^{1}$} \\
\hline Norte Grande & $126(100-159)$ & $130(112-169)$ & $85(55-132)$ & $95(72-143)$ \\
\hline Norte Chico & $56(42-75)$ & $77(64-96)$ & $54(34-86)$ & $78(58-109)$ \\
\hline Zona Central $^{2}$ & $105(99-112)$ & $104(99-110)$ & $106(96-116)$ & $105(98-116)$ \\
\hline Zona Sur & $86(74-101)$ & $77(68-89)$ & $98(78-124)$ & $79(98-116)$ \\
\hline Zona Austral & $85(50-143)$ & $94(66-152)$ & $88(39-195)$ & $122(74-257)$ \\
\hline Santiago Metropolitan Region & $128(118-139)$ & $114(108-125)$ & $122(107-139)$ & $109(100-126)$ \\
\hline \multicolumn{5}{|l|}{ Health Service area } \\
\hline Arica & $76(42-137)$ & $87(59-127)$ & $99(45-221)$ & $57(27-119)$ \\
\hline Iquique & $145(95-220)$ & $131(98-176)$ & $95(43-212)$ & $150(98-230)$ \\
\hline Antofagasta & $142(104-196)$ & $153(124-188)$ & $72(36-144)$ & $83(54-129)$ \\
\hline Atacama & $32(14-71)$ & $106(75-149)$ & $38(12-118)$ & $116(70-193)$ \\
\hline Coquimbo & $64(47-88)$ & $69(55-86)$ & $60(36-99)$ & $66(46-95)$ \\
\hline Valpo-SnAntonio & $87(63-120)$ & $74(58-94)$ & $57(31-106)$ & $91(64-127)$ \\
\hline Viña-Quillota & $79(63-99)$ & $97(84-112)$ & $105(77-143)$ & $101(81-126)$ \\
\hline Aconcagua & $112(76-166)$ & $118(89-156)$ & $76(36-160)$ & $84(50-141)$ \\
\hline Metropolitana Norte & $151(119-191)$ & $112(95-133)$ & $143(98-208)$ & $91(68-122)$ \\
\hline Metropolitana Occidental & $131(107-161)$ & $94(80-110)$ & $149(111-201)$ & $115(92-143)$ \\
\hline Metropolitana Central & $132(106-165)$ & $128(111-147)$ & $120(83-173)$ & $118(94-149)$ \\
\hline Metropolitana Ote & $125(106-149)$ & $120(108-132)$ & $110(83-146)$ & $103(87-123)$ \\
\hline Metropolitana Sur & $158(133-189)$ & $129(114-146)$ & $152(115-202)$ & $143(120-172)$ \\
\hline Metropolitana Sur Ote & $93(76-115)$ & $96(83-111)$ & $83(59-116)$ & $81(63-103)$ \\
\hline O’Higgins & $83(65-107)$ & $111(93-132)$ & $91(62-132)$ & $123(95-158)$ \\
\hline Maule & $86(68-109)$ & $90(75-107)$ & $86(60-124)$ & $92(70-121)$ \\
\hline Ñuble & $71(48-103)$ & $99(78-126)$ & $63(34-117)$ & $127(91-176)$ \\
\hline Concepción & $108(79-147)$ & $85(68-106)$ & $136(89-208)$ & $106(78-144)$ \\
\hline Arauco & $63(32-127)$ & $45(23-86)$ & $77(29-204)$ & $24(6-96)$ \\
\hline Talcahuano & $77(52-114)$ & $66(47-93)$ & $97(56-167)$ & $84(53-134)$ \\
\hline Bío-Bío & $50(31-82)$ & $61(43-86)$ & $76(41-141)$ & $85(54-133)$ \\
\hline Araucanía Norte & $88(55-140)$ & $80(55-115)$ & $119(64-221)$ & $110(68-180)$ \\
\hline Araucanía Sur & $92(71-119)$ & $75(61-93)$ & $125(88-176)$ & $78(56-107)$ \\
\hline Valdivia & $119(87-163)$ & $77(58-103)$ & $89(50-156)$ & $77(49-121)$ \\
\hline Osorno & $57(32-103)$ & $83(59-118)$ & $50(19-134)$ & $50(25-101)$ \\
\hline Reloncaví & $78(50-121)$ & $92(68-123)$ & $103(57-186)$ & $128(87-190)$ \\
\hline Chiloé & $46(22-96)$ & $42(23-76)$ & $32(8-127)$ & - \\
\hline Aisén & $102(46-227)$ & $81(42-155)$ & $123(40-380)$ & $109(45-262)$ \\
\hline Magallanes & $75(38-151)$ & $101(66-155)$ & $68(22-211)$ & $128(71-231)$ \\
\hline
\end{tabular}

${ }^{1}$ Chile can be divided into five 'natural regions'. Since these include subregions, the following definitions were used. Norte Grande: Arica, Iquique, Antofagasta; Norte Chico: Atacama, Coquimbo; Zona Central: ValpoSnAntonio, Viña-Quillota, Aconcagua, Metropolitana, O’Higgins, Maule, Ñuble, Concepción, Arauco, Talcahuano, Bío-Bío; Zona Sur: Araucanía, Valdivia, Osorno, Reloncaví, Chiloé; Zona Austral: Aisén, Magallanes.

${ }^{2}$ Including the Santiago Metropolitan Region.

of death certification rather than to factors relevant to specific illnesses. Also, accuracy of reporting may vary between countries.

Many people in the community with dementia are not formally diagnosed [23]. Since it is necessary to have a diagnosis for it to be recorded on a death certificate, it is possible that variation in diagnosis rates across a country could have influenced our findings. This is partic- 


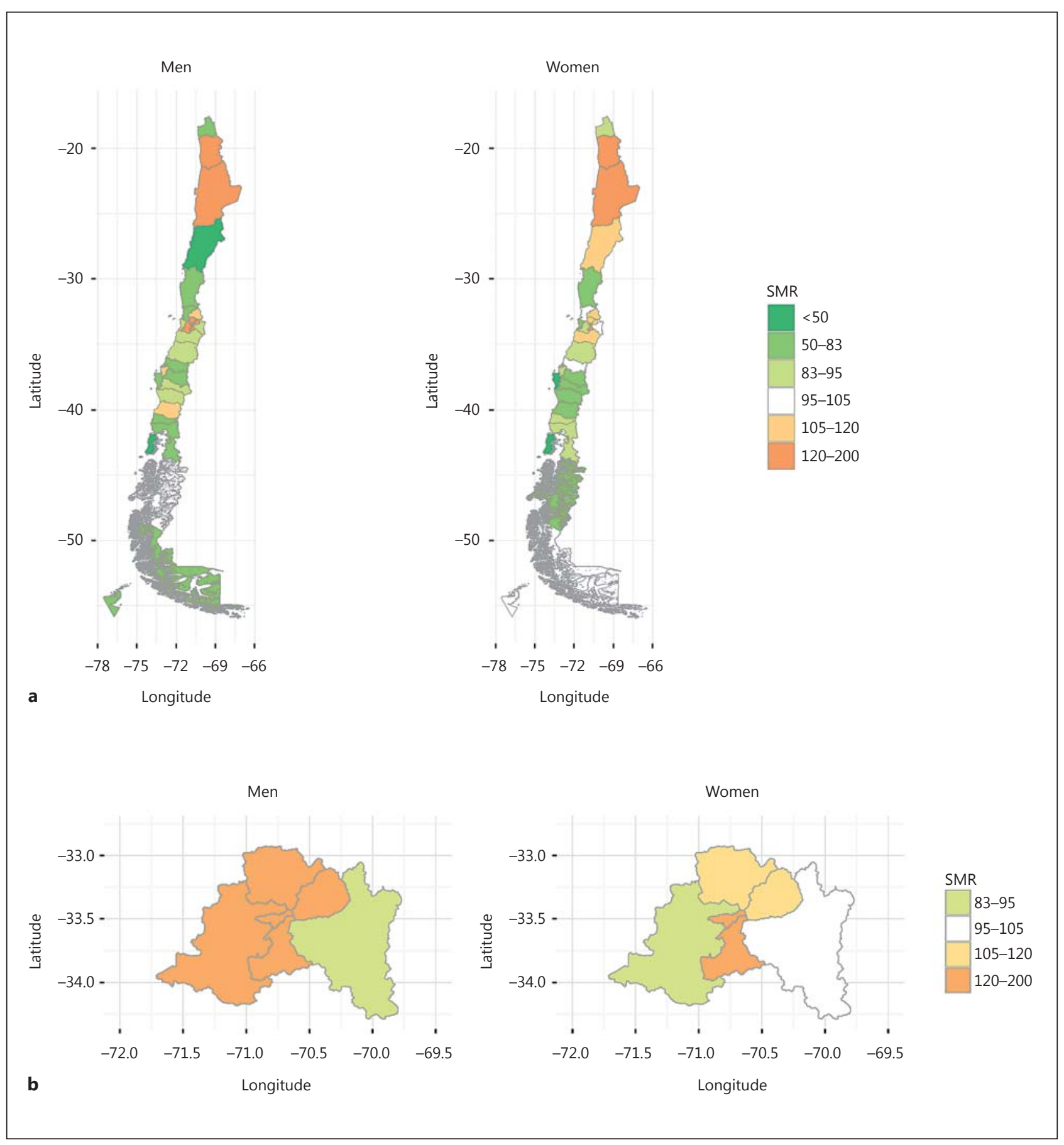

Fig. 3. a Dementia SMRs by Health Service area of Chile for men and women. b Dementia SMRs by Health Service area of Chile for men and women: Santiago Metropolitan Region.

ularly the case in countries such as Chile that have undergone rapid demographic change over the last two decades, requiring substantial adaptation by the health services. Indeed, a recent survey suggested that Chilean physicians generally have poor training in dementia [24]. Therefore, it is possible that the observed differences in dementia mortality between the south and the central region (i.e., the capital of Chile) could be partly explained by expertise 
of physicians in relation to dementia. Furthermore, there may be cultural differences in that individuals in some areas may not want the diagnosis of dementia to appear on their relative's death certificate. However, the consistent pattern seen in a number of different countries adds weight to the hypothesis that the observed geographical variation may represent a real effect. Moreover, it seems unlikely that the difference in mortality rate between the south and north of Chile, for example, could be explained solely by accuracy of death certification.

The data used included residential location at death, which may have biased our findings since the probability of being in residential care increases steeply in later life, leading to the danger of simply mapping the residential care facilities. However, the large areas used for each country are likely to have minimised this bias, as a large proportion of people would probably remain in the area in which they had previously lived. Furthermore, one previous study reported increased dementia mortality rates in those born on the north side of Bonavista Bay in Newfoundland compared to the south [9]. Another study in Scotland found no geographical variation in dementia rates based on county of school attended at age 11 years, but substantial variation based on residential location five or six decades later [12]. Birth records were accessed for a subsample and 79\% had attended school in their county of birth.

Finally, as with all ecological studies, we should be cautious in inferring that these observed associations are causal or that they will still apply at the level of the individual. Nevertheless, accumulating evidence from numerous countries using different methodologies strongly suggests that our findings deserve further attention.

\section{Possible Mechanisms}

It was not been here to examine the effect of relevant covariables (education, socioeconomic status, etc.) on geographical variation in dementia rates. However, a twin study previously found that this substantial variation remained even after the removal of genetic and shared environmental variance, potentially implicating one or more unshared environmental factors [12]. One environmental risk factor in which there is growing interest is sunlight exposure (and consequently vitamin D levels) [13]. Four prospective studies including almost 17,000 individuals all found that lower vitamin D levels at baseline were associated with an increased risk of developing dementia [14-17]. Another prospective study found that people with vitamin D deficiency showed faster cognitive decline than individuals with sufficient levels [25]. Furthermore, a case-control study found an association between polymorphisms in the vitamin D receptor gene and the presence of Alzheimer's disease [26]. Our finding that dementia rates are higher in the north of the northern hemisphere would be consistent with the hypothesis that vitamin D - or other light-related mechanisms, for example UVB mobilisation of nitric oxide [27] or the potential relation between latitude and affect [28] - may be important in the pathogenesis of dementia. However, the evidence from the southern hemisphere is more mixed.

There are several ways in which vitamin D could be involved in the development of Alzheimer's disease, including neuroprotection, regulation of neurotrophic factors, its involvement in calcium homeostasis, and its effects on the immune system through cytokine regulation [29]. Our findings from the southern hemisphere might possibly be explained by higher mean serum concentrations of 25-hydroxyvitamin D in older adults in Chile 75.5 $\mathrm{nmol} / \mathrm{l}$ ) [30] and New Zealand (general population 60.5-65.1 nmol/l) [31] compared to Italy (37.9 nmol/l) [32]. For example, if vitamin D had a neuroprotective effect, higher mean levels in the population could diminish the effect of variation in serum levels with latitude on dementia risk. A national survey from New Zealand found higher mean levels of vitamin $D$ in the northern region compared to central and southern regions, but no difference in prevalence of vitamin D deficiency between the three regions after adjusting for age, sex, and ethnic group [31]. 
Russ et al.: Geographical Variation in Dementia Mortality in Italy, New Zealand, and Chile: The Impact of Latitude, Vitamin D, and Air Pollution

There are also alternative mechanisms which may explain part of the reported patterns. For example, the increased dementia risk in the Santiago Metropolitan Region may be related to air pollution, many aspects of which - nitrogen oxides, carbon monoxide, particulate matter $\left(\mathrm{PM}_{10}\right.$ and $\left.\mathrm{PM}_{2.5}\right)$, and ozone - have been related to dementia risk [33-35]. There is further supporting evidence from another large metropolitan area: a recent study found a biomarker which has been proposed for Alzheimer's disease [36] (reduced cerebrospinal fluid levels of $A \beta_{1-42}$ ) in children from Mexico City who had been exposed to high levels of air pollution in utero and throughout their life compared to controls [37]. Other mechanisms are also possible, for example a high cancer risk was identified in Antofagasta in the north of Chile in relation to historical high levels of arsenic in drinking water, demonstrating that environmental exposures can have long-lasting effects on health [38].

There is evidence for geographical stratification of genetic heritage, at least in Scotland [39]. Similarly, the proportion of people carrying the APOE $\varepsilon 4$ allele is higher in northern Europe than southern Europe, which may explain some of the observed variation in dementia risk [40]. Excluding Maori and Pacific peoples from our New Zealand analyses should have ensured broad comparability in terms of genetic heritage with Italy; a similar process was not possible for Chile, which may partially explain the differing results. However, a twin study in Sweden showed geographical variation in dementia risk of a similar size in monozygotic twins discordant for dementia, implying that whatever the explanation for this finding is, it cannot be solely genetic [12].

Finally, as mentioned above, a further possible mechanism relates to affective disorders. Both psychological distress and depression have been linked with dementia risk [41, 42]. Psychiatric disorder has been shown to vary by region in Chile, with a high incidence of depression in Tarapacá and Metropolitana, regions with raised dementia SMRs in the present study [43].

\section{Conclusions}

We found increased dementia SMRs in the north of Italy compared to the south, consistent with similar studies from across the northern hemisphere. In New Zealand and Chile, we saw a more complex pattern, with some evidence of an inverse pattern, in women at least, in New Zealand and an increased risk in some northern areas of Chile. Further, more detailed work examining the epidemiology of dementia in the southern hemisphere is needed, but these findings add weight to the hypothesis that dementia risk varies with geography (and probably latitude). We have also proposed two plausible environmental risk factors which may explain our findings: sunlight (and vitamin D) and air pollution.

\section{Acknowledgements}

The authors are grateful to Chris Lewis, Information Analyst from the New Zealand Ministry of Health, for providing the mortality data for New Zealand.

T.C. Russ and J.M. Starr are members of both the Alzheimer Scotland Dementia Research Centre funded by Alzheimer Scotland and the University of Edinburgh Centre for Cognitive Ageing and Cognitive Epidemiology, part of the cross-council Lifelong Health and Wellbeing Initiative (G0700704/84698). Funding by the Biotechnology and Biological Sciences Research Council, Engineering and Physical Sciences Research Council, Economic and Social Research Council, and Medical Research Council is gratefully acknowledged for the latter. T.C. Russ is supported by Alzheimer Scotland through the Marjorie MacBeath fellowship. A. Slachevsky is supported by CONICYT/FONDAP/15150012.

This work was supported by Alzheimer Scotland (charity). 
Russ et al.: Geographical Variation in Dementia Mortality in Italy, New Zealand, and Chile: The Impact of Latitude, Vitamin D, and Air Pollution

\section{Disclosure Statement}

The authors have no conflicts of interest to declare. All of them are independent of the funders, who played no role in this study.

\section{References}

1 Prince M, Wimo A, Guerchet M, Ali GC, Wu YT, Prina M: World Alzheimer Report 2015: The Global Impact of Dementia. London, Alzheimer's Disease International, 2015. https://www.alz.co.uk/research/worldreport-2015.

2 Iadecola C: The overlap between neurodegenerative and vascular factors in the pathogenesis of dementia. Acta Neuropathol 2010;120:287-296.

-3 Ritchie CW, Molinuevo JL, Truyen L, Satlin A,Van der Geyten S, Lovestone S; European Prevention of Alzheimer's Dementia (EPAD) Consortium: Development of interventions for the secondary prevention of Alzheimer's dementia: the European Prevention of Alzheimer's Dementia (EPAD) project. Lancet Psychiatry 2016;3:179186.

-4 Ridge PG, Mukherjee S, Crane PK, Kauwe JSK; Alzheimer's Disease Genetics Consortium: Alzheimer's disease: analyzing the missing heritability. PLoS One 2013;8:e79771.

5 Norton S, Matthews FE, Barnes DE, Yaffe K, Brayne C: Potential for primary prevention of Alzheimer's disease: an analysis of population-based data. Lancet Neurol 2014;13:788-794.

6 Russ TC, Batty GD, Hearnshaw GF, Fenton C, Starr JM: Geographical variation in dementia: systematic review with meta-analysis. Int J Epidemiol 2012;41:1012-1032.

7 Sulkava R, Wikstrom J, Aromaa A, Raitasalo R, Lehtinen V, Lahtela K, Palo J: Prevalence of severe dementia in Finland. Neurology 1985;35:1025-1029.

8 Sulkava R, Heliövaara M, Palo J, Wikström J, Aromaa A: Regional differences in the prevalence of Alzheimer's disease; in Soininen H (ed): Proceedings of the International Symposium on Alzheimer's Disease, June 12-15, 1988, Kuopio, Finland: Department of Neurology, University of Kuopio. Finland, World Federation of Neurology Research Group on Dementia, 1988, p 8.

-9 Frecker MF: Dementia in Newfoundland: identification of a geographical isolate? J Epidemiol Community Health 1991;45:307-311.

10 Wu YT, Lee HY, Norton S, Chen C, Chen H, He C, Fleming J, Matthews FE, Brayne C: Prevalence studies of dementia in mainland China, Hong Kong and Taiwan: a systematic review and meta-analysis. PLoS One 2013; 8:e66252.

11 Starr JM: Changes in dementia prevalence: implications for public health. J R Coll Physicians Edinb 2014;44: 29.

12 Russ TC, Gatz M, Pedersen NL, Hannah J, Wyper G, Batty GD, Deary IJ, Starr JM: Geographical variation in dementia: examining the role of environmental factors in Sweden and Scotland. Epidemiology 2015;26:263270.

13 Annweiler C, Llewellyn DJ, Beauchet 0: Low serum vitamin D concentrations in Alzheimer's disease: a systematic review and meta-analysis. J Alzheimers Dis 2013;33:659-674.

14 Annweiler C, Rolland Y, Schott AM, Blain H, Vellas B, Beauchet O: Serum vitamin D deficiency as a predictor of incident non-Alzheimer dementias: a 7-year longitudinal study. Dement Geriatr Cogn Disord 2011;32:273278.

15 Afzal S, Bojesen SE, Nordestgaard BG: Reduced 25-hydroxyvitamin D and risk of Alzheimer's disease and vascular dementia. Alzheimers Dement 2014;10:296-302.

-16 Littlejohns TJ, Henley WE, Lang IA, Annweiler C, Beauchet O, Chaves PH, Fried L, Kestenbaum BR, Kuller LH, Langa KM, Lopez OL, Kos K, Soni M, Llewellyn DJ: Vitamin D and the risk of dementia and Alzheimer disease. Neurology 2014;83:920-928.

17 Knekt P, Sääksjärvi K, Järvinen R, Marniemi J, Männistö S, Kanerva N, Heliövaara M: Serum 25-hydroxyvitamin D concentration and risk of dementia. Epidemiology 2014;25:799-804.

18 Kirkwood BR, Sterne JAC: Essential Medical Statistics, ed 2. Oxford, Blackwell, 2003.

19 Wickham H: ggplot2: Elegant Graphics for Data Analysis. New York, Springer, 2009.

20 Russ TC, Batty GD, Starr JM: Cognitive and behavioural predictors of survival in Alzheimer disease: results from a sample of treated patients in a tertiary-referral memory clinic. Int J Geriatr Psychiatry 2012;27:844853.

-21 Russ TC, Starr JM, Stamatakis E, Kivimaki M, Batty GD: Pulmonary function as a risk factor for dementia death: an individual participant meta-analysis of six UK general population cohort studies. J Epidemiol Community Health 2015;69:550-556.

22 Martyn CN, Pippard EC: Usefulness of mortality data in determining the geography and time trends of dementia. J Epidemiol Community Health 1988;42:134-137.

23 Sampson EL, Blanchard MR, Jones L, Tookman A, King M: Dementia in the acute hospital: prospective cohort study of prevalence and mortality. Br J Psychiatry 2009;195:61-66. 
Russ et al.: Geographical Variation in Dementia Mortality in Italy, New Zealand, and Chile: The Impact of Latitude, Vitamin D, and Air Pollution

24 Olavarria L, Mardones C, Delgado C, Slachevsky A: Chilean health professionals perception of knowledge about dementia. J Neurol Sci 2015;357(suppl 1):e134.

25 Llewellyn DJ, Lang IA, Langa KM, Muniz-Terrera G, Phillips CL, Cherubini A, Ferrucci L, Melzer D: Vitamin D and risk of cognitive decline in elderly persons. Arch Intern Med 2010;170:1135-1141.

26 Gezen-Ak D, Dursun E, Ertan T, Hanagasi H, Gürvit H, Emre M, Eker E, Öztürk M, Engin F, Yilmazer S: Association between vitamin D receptor gene polymorphism and Alzheimer's disease. Tohoku J Exp Med 2007;212: 275-282.

27 Feelisch M, Kolb-Bachofen V, Liu D, Lundberg JO, Revelo LP, Suschek CV, Weller RB: Is sunlight good for our heart? Eur Heart J 2010;31:1041-1045.

28 Inoue T, Kohno K, Baba H, Takeshima M, Honma H, Nakai Y, Suzuki T, Hatano K, Arai H, Matsubara S: Does temperature or sunshine mediate the effect of latitude on affective temperaments? A study of 5 regions in japan. J Affect Disord 2015;172:141-145.

29 Gezen-Ak D, Yilmazer S, Dursun E: Why vitamin D in Alzheimer's disease? The hypothesis. J Alzheimers Dis 2014;40:257-269.

-30 Lips P, Hosking D, Lippuner K, Norquist JM, Wehren L, Maalouf G, Ragi-Eis S, Chandler J: The prevalence of vitamin D inadequacy amongst women with osteoporosis: an international epidemiological investigation. J Intern Med 2006;260:245-254.

31 Ministry of Health: Vitamin D status of New Zealand adults. Findings from the 2008/09 New Zealand Adult Nutrition Survey. Wellington, Ministry of Health, 2012. https://www.health.govt.nz/system/files/documents/publications/vit-d-status-nzadults.pdf.

32 Adami S, Viapiana O, Gatti D, Idolazzi L, Rossini M: Relationship between serum parathyroid hormone, vitamin D sufficiency, age, and calcium intake. Bone 2008;42:267-270.

-33 Oudin A, Forsberg B, Nordin Adolfsson A, Lind N, Modig L, Nordin M, Nordin S, Adolfsson R, Nilsson LG: Trafficrelated air pollution and dementia incidence in northern Sweden: a longitudinal study. Environ Health Perspect 2016;124:306-312.

34 Chang KH, Chang MY, Muo CH, Wu TN, Chen CY, Kao CH: Increased risk of dementia in patients exposed to nitrogen dioxide and carbon monoxide: a population-based retrospective cohort study. PLoS One 2014;9: e103078.

-35 Wu YC, Lin YC, Yu HL, Chen JH, Chen CD, Chen TF, Sun Y, Wen LL, Yip PK, Chu YM: Association between air pollutants and dementia risk in the elderly. Alzheimers Dement (Amst) 2015;1:220-228.

-36 Ritchie C, Smailagic N, Noel-Storr AH, Takwoingi Y, Flicker L, Mason SE, McShane R: Plasma and cerebrospinal fluid amyloid beta for the diagnosis of Alzheimer's disease dementia and other dementias in people with mild cognitive impairment (MCI). Cochrane Database Syst Rev 2014;6:CD008782.

37 Calderón-Garcidueñas L, Chao C, Thompson C, Rodríguez-Díaz J, Franco-Lira M, Mukherjee PS, Perry G: CSF biomarkers: low amyloid- $\beta_{1-42}$ and BDNF and high IFN $\gamma$ differentiate children exposed to Mexico City high air pollution v controls. Alzheimer's disease uncertainties. J Alzheimers Dis Parkinsonism 2015;5:189.

-38 Steinmaus CM, Ferreccio C, Romo JA, Yuan Y, Cortes S, Marshall G, Moore LE, Balmes JR, Liaw J, Golden T, Smith $\mathrm{AH}$ : Drinking water arsenic in northern Chile: high cancer risks 40 years after exposure cessation. Cancer Epidemiol Biomarkers Prev 2013;22:623-630.

-39 Amador C, Huffman J, Trochet H, Campbell A, Porteous D, Wilson JF, Hastie N, Vitart V, Hayward C, Navarro P: Recent genomic heritage in Scotland. BMC Genomics 2015;16:437.

40 Gerdes LU: The common polymorphism of apolipoprotein E: geographical aspects and new pathophysiological relations. Clin Chem Lab Med 2003;41:628-631.

-41 Russ TC, Hamer M, Stamatakis E, Starr JM, Batty GD: Psychological distress as a risk factor for dementia death. Arch Intern Med 2011;171:1858-1859.

42 Prince M, Albanese E, Guerchet M, Prina M: World Alzheimer Report 2014: Dementia and Risk Reduction. London, Alzheimer's Disease International, 2014. https://www.alz.co.uk/research/world-report-2014.

-43 Vicente B, Kohn R, Rioseco P, Saldivia S, Navarrette G, Veloso P, Torres S: Regional differences in psychiatric disorders in Chile. Soc Psychiatry Psychiatr Epidemiol 2006;41:935-942. 